\title{
Exploring barriers to family planning service utilization and uptake among women in Iraq
}

Yousuf Alrawi ${ }^{1}$

United Nations Population Fund, Eritrea Country Office, Asmara, Eritrea (Correspondence to: Yousuf Alrawi: alrawi@unfpa.org).

\begin{abstract}
Background: Family planning helps to avoid unwanted pregnancy and reduce maternal mortality and morbidity. Contraceptive prevalence is still relatively low (58\%) in Iraq compared with other countries in the Eastern Mediterranean Region, and the unmet need (12\%) and total fertility (4.2 children per woman) rates are still high. Services are available free of charge or heavily subsidized in many public and private health facilities, yet many women may still not use them due to social, cultural, financial or health care services constraints.
\end{abstract}

Aims: This scoping review explores barriers to family planning services utilization and uptake among women in Iraq.

Methods: The review uses an adapted conceptual framework from quality of care and human rights-based frameworks to analyse published scientific studies.

Results: At policy level, the government has supported family planning but not enough resources were allocated. At the service level, low family planning promotion from health care providers (especially during antenatal care visits) along with provider bias for certain types of contraception, have contributed to inaccurate information and misconceptions. At the community and individual level, women's choice is still largely influenced by the husband's position on contraception as men are still considered the key decision-makers in regard to fertility. Valuing a large family is still a barrier to family planning services utilization and uptake whereas religion was found to support the use of family planning.

Conclusion: There is a need to provide promotional messages and encouraging mutual fertility decisions.

Keywords: family planning, barriers, health care services, Iraq

Citation: Alrawi Y. Exploring barriers to family planning service utilization and uptake among women in Iraq. East Mediterr Health J. 2021;27(8):818-825. https://doi.org/10.26719/emhj.21.015

Received: 04/02/20; accepted: 20/12/20

Copyright (C) World Health Organization (WHO) 2021. Open Access. Some rights reserved. This work is available under the CC BY-NC-SA 3.0 IGO license (https://creativecommons.org/licenses/by-nc-sa/3.o/igo).

\section{Introduction}

According to the World Health Organization (WHO), family planning (FP) is the planned use of contraception to decide the timing and the number of children that couples want to have (1). Use of FP helps to avoid unwanted pregnancy, reduce maternal morbidity and mortality by one-third and reduce poverty and hunger (1) by supporting women's economic empowerment and education and their ability to make decisions (2). Contraceptive prevalence is defined by WHO as the percentage of married or in-union women who are using any method (traditional or modern) of contraception (1).

In Iraq, prevalence of contraceptive use is $58 \%$ ( $44 \%$ modern, $14 \%$ traditional), which is lower than the global average $(63 \%)$ and also lower than other countries in the Region such as Jordan (63\%) and Tunisia (67\%) (3). The unmet need and the demand satisfied for modern methods are estimated to be $12 \%$ and $63 \%$ respectively, and the total fertility rate is currently 4.2 children per woman compared with 2.5 globally (3). Furthermore, inequities still exist in FP utilization, with contraceptive prevalence being lower among women in rural areas, women from the poorest quintile or women who have primary or no education; prevalence is higher in women in the Kurdistan region (4).
Family planning services are intended to be offered free of charge or heavily subsidized in many primary health centres and FP centres in public hospitals (5). In addition, the private sector, such as pharmacies and private clinics, also plays a significant role, especially in providing FP commodities such as oral pills and intrauterine device (IUD) insertion and removal (5). The most commonly used FP method in Iraq is oral pills ( $50 \%$ of all modern methods) followed by IUDs $(25 \%)$ and injectables (10\%) (6).

However, even with the availability of FP services and methods, women may still not use them owing to social, cultural, financial or health care service constraints (5), yet research on these constraints is still very limited in Iraq. This scoping review aimed to examine policy, health system, cultural and social factors that hinder utilization and uptake of FP services among Iraqi women (from both supply and demand sides) to understand the current barriers. As far as is known, this is the first review of this kind in Iraq; it will help to inform policy and programme development.

\section{Methods}

This is a scoping review on the current barriers to family planning services utilization and uptake among women 
in Iraq; it is based on secondary data captured from published scientific studies. We adjusted 2 existing frameworks to produce an adapted conceptual framework: the Human Rights-Based Family Planning Conceptual Framework (7) identifies the required input at the country context, policy, service, community and individual levels to ensure equitable access to services and people making informed choices and the Fundamental Elements of the Quality of Care (8) incorporates elements of quality of care into the service level to assess the role of FP services quality. The adapted conceptual framework guided the literature search and review (Figure 1); it offers a practical holistic and health system approach to planning and implementing FP programmes incorporating human rights and quality of care.

Different combinations of key terms were used divided into 3 groups to reflect the different terminologies of the topic and different programmatic interventions in Iraq or countries with a similar context (Figure 2). These key terms were used to capture as much data as possible about FP services and barriers in Iraq and in countries with similar socioeconomic and cultural context (to compare it with the context of Iraq).

Inclusion and exclusion criteria were used: literature relevant to Iraq and its context; published after 2005 (older literature has little relevance); in Arabic or English (so it can be read by the author) and free or accessible. The date filter was removed during the search for the conceptual framework (to find the most relevant) and during the search in policy level to assess the stance of different governments in Iraq on FP.

Databases such as PubMed, Popline, Google Scholar, Global Health, BMC Women's Health and the Iraqi Academic Scientific Journals database were searched between March 2019 and July 2019 as part of the Master of Public Health (MPH) thesis to capture all studies at the local level that were published on the topic. Also, grey literature from situation reports and national surveys from the Ministry of Health and Environment, WHO, the United Nations Population Fund and other organizations were used; these provided studies about FP programmes and services in Iraq.

An example from searches in PubMed, Popline and Global Health resulted in 157 records. After applying the exclusion criteria and removing duplicates, 82 abstracts were screened. Finally, 58 full-text studies were assessed for relevance and 34 were included in this review.

\section{Results}

\section{Country context}

Over the last few decades, the Iraqi population has continued to increase, with an average annual growth rate of $3 \%$ (3) which is considered among the highest in the Region along with Yemen and Palestine (9). Currently, $70 \%$ of the population live in urban areas (10) and women aged $15-49$ years form about $20 \%$ of the total population (11). Poverty and unemployment remain high with $22 \%$ of the total population live below the national poverty line (12) and with a relatively high maternal mortality rate (50 deaths per 100000 live births) (3). Inequalities exist: the poverty rate is double in rural areas, $22 \%$ of women are illiterate (5) and account for only $10 \%$ of the workforce (12).

Civil conflict and political instability had a detrimental effect on the health care system and have weakened its capacity to respond to the needs of people (Table 1) (13). The effects within the reproductive health services include lack of appropriate infrastructure, poor referral

\section{Figure 1 Conceptual framework for the literature search on family planning (FP)}

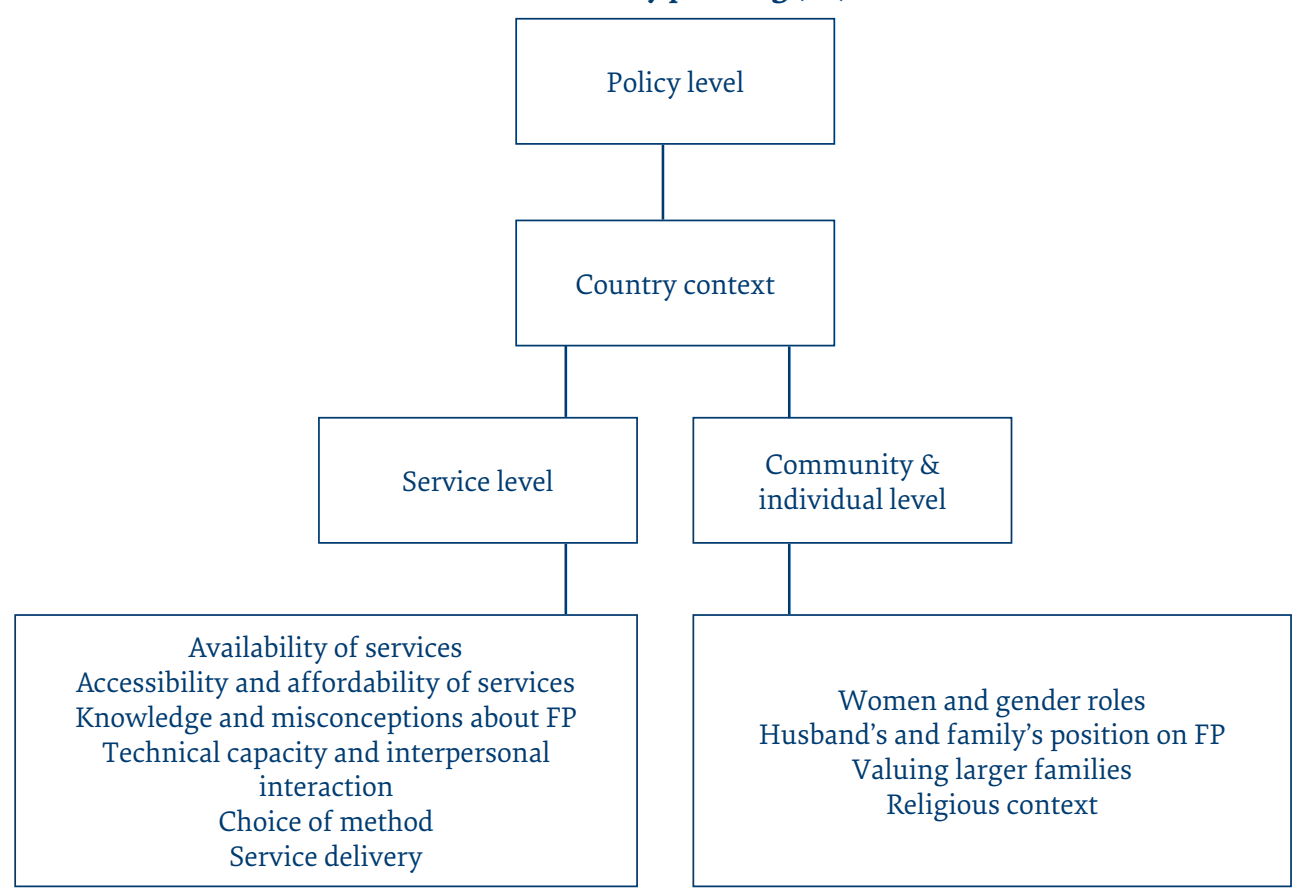


Figure 2 Summary of the key terms used for the literature search on family planning

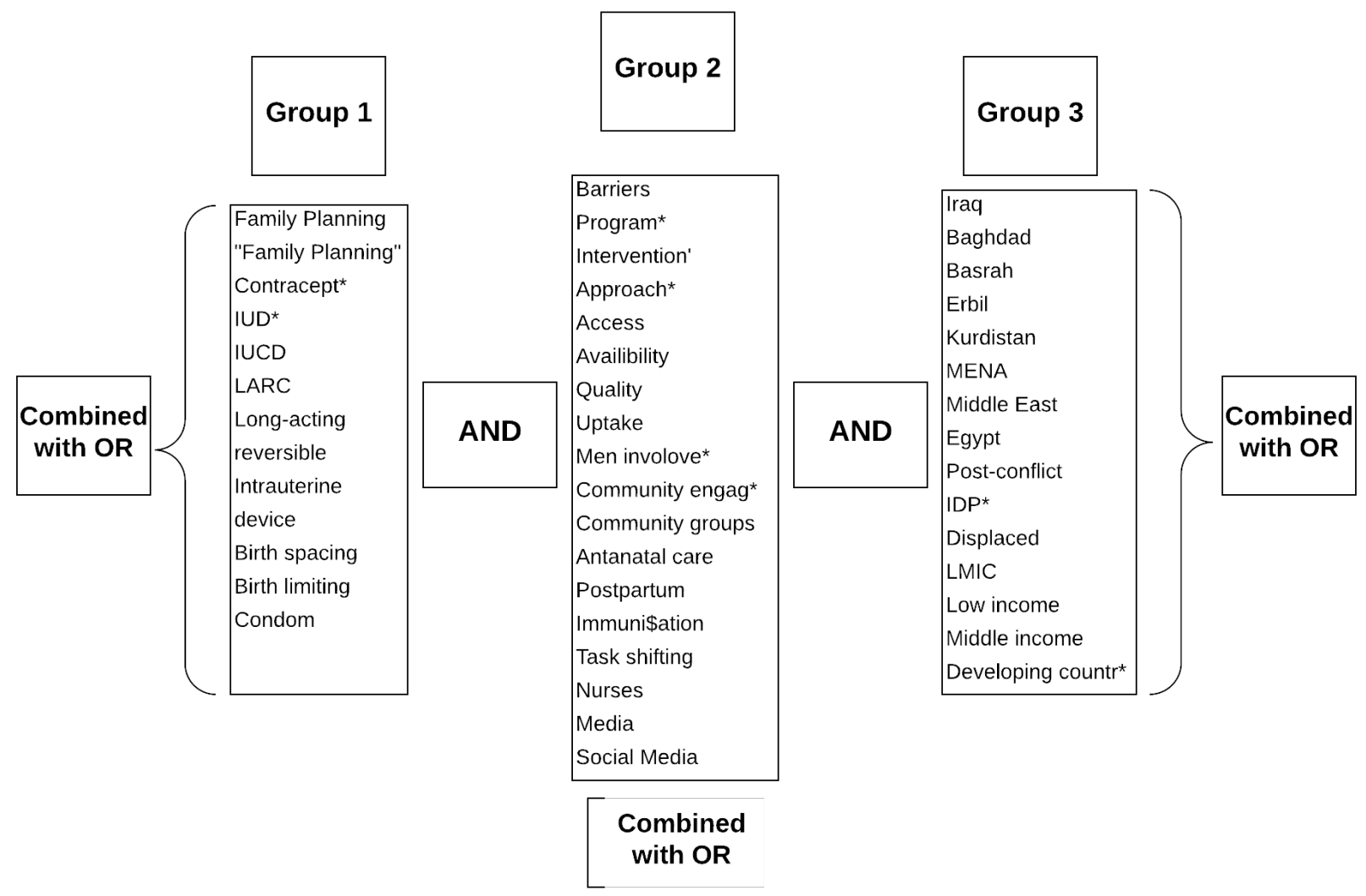

systems, reduced quality of care and violent attacks targeting health care providers (14). Also, the recent humanitarian crisis (2014 and after) resulted in shortages in supplies and commodities and many health personnel and more than 3 million people fleeing their homes (15).

\section{Policy level}

Access to FP services had been restricted by previous policies before 2003 in which the previous administration emphasized the importance of reproduction and incentivized having more children as the country was going through wars (16). When the major political transition took place in 2003 , the new government politically supported FP programmes (16) but little or no effort was made to support implementation (Table 1) (5). Currently, the Ministry of Health and Environment does not have a separate policy or strategy on FP in place but FP was addressed and included in the National Health Plan in 2010 (12) and the National Reproductive, Maternal, Neonatal, Child and Adolescent Health Strategy 2016-2020 (17). They both highlighted the importance of providing quality FP services, including ensuring the availability of contraception commodities, building the capacity of health care providers and improving monitoring and accountability.

\section{Service level}

\section{Availability of services}

Family planning services are supposed to be offered in primary health centres and public hospitals free of charge or heavily subsidized (5). However, FP commodities are sometimes unavailable or are misappropriated from the public to the private sector, and many women have to depend on private pharmacies and clinics to purchase contraception in most areas of the country (5), including the Kurdistan region (18). Currently, only $5 \%$ of women have reported public facilities as their source for contraception in I-WISH national survey (19).

\section{Accessibility and affordability of family planning services}

There are very few studies on the affordability of FP services and methods. The Central Statistical Organization in Iraq published a document in 2011 which reported that the affordability of commodities accounted for less than $5 \%$ of problems among women using contraception (6). From the search conducted for this report, no published information was found among women not using contraception on FP affordability and services accessibility, including in surveys and field assessments from the Ministry of Health and other organizations about the need among vulnerable groups (displaced women, those in rural areas) and accessibility for these groups.

\section{Knowledge and education about family planning services and methods}

Although knowledge about FP and its methods is generally good among women (6), this varies between different governorates $(5,20)$ and from one method to another; oral pills and IUDs are more commonly known compared with condoms, injectables and other methods (21). 


\begin{tabular}{ll}
\hline $\begin{array}{l}\text { Table } 1 \text { Summary of barriers to family planning services } \\
\text { utilization in Iraq }\end{array}$ & Barriers \\
\hline Level & $\begin{array}{l}\text { Unstable security, conflict and } \\
\text { displacement } \\
\text { Damage to health facilities }\end{array}$ \\
\hline Country context & $\begin{array}{l}\text { Not enough resources allocated for } \\
\text { implementation. }\end{array}$ \\
Policy level & $\begin{array}{l}\text { Misconceptions and lack of accurate } \\
\text { information } \\
\text { Lack of family planning promotion by } \\
\text { health care providers } \\
\text { Gender norms and valuing large families } \\
\text { Women unable to make decisions about } \\
\text { family size }\end{array}$ \\
\hline
\end{tabular}

Furthermore, there was a lack of promotional messages such as counselling, leaflets or other methods from health care providers. In the capital, Baghdad, most women said they had not received any information about FP during their visits to the primary health centres (22). Similar findings were reported in Basrah, where only 50\% of participants cited health care providers as the source of their contraception information (other sources were family and friends) (5).

Education about correct use was also found to be suboptimal and still needs improvement: some women in Mosul stated that they did not know how to use contraception as the reason for their unmet need for FP (23). Furthermore, $20 \%$ of unwanted pregnancies were among women who failed to use contraception correctly in Duhok (18) and Mosul (23), which might also support the lack of accurate information about contraception and its correct use.

\section{Misconceptions about family planning}

Misconceptions about FP and contraception were identified as preventing women from seeking FP services (Table 1). About $50 \%$ of the non-users mentioned health reasons and side-effects such as cancer or infertility for not using any contraception in studies in Basrah (5) and Mosul (23).

Many women said they do not receive enough information about $\mathrm{FP}$ from health care providers. Women attending antenatal care in Erbil reported that they had specific questions about contraception but health care providers did not give them sufficient time to address their concerns (14).

\section{Technical capacity and interaction of providers}

From the search conducted for this report, no published studies were found looking into provider-client interaction or the technical knowledge and skills of health care professionals in providing FP services. However, one study in Erbil reported that the average consultation with a doctor took just 2 minutes in the primary health centres, during which the patient received treatment or was referred to hospitals (24).

\section{Choice of method}

Although FP services and supplies are meant to be offered in primary health centres, most of them fall short in providing contraception, which means women rely on private clinics and pharmacies to buy contraception commodities (5). The Multiple Indicator Cluster Survey shows that almost all the contraception methods are available in the private sector (4) but women in one study reported provider bias as they used a specific method due to the provider's preference for one method over the others (20).

\section{Service delivery}

Women can get FP consultation through health facilities but most would have to buy contraception commodities from private pharmacies and clinics due the lack of availability (5). On the other hand, many women in one study said that they preferred to go to private clinics for the consultation because of the shorter waiting time and better quality of services (14).

Promotion of FP was also included in antenatal and postpartum care visits to promote post-delivery contraception (25). It was reported that only $50 \%$ of women received FP counselling during antenatal care in Erbil (25) but no studies were found on FP counselling during postpartum visits. Furthermore, there are no published reports or information about any guidelines or in-service training for health care providers and no studies on FP counselling during postpartum visits.

\section{Community and individual level}

\section{Women and gender roles}

According to the social norms in Iraq, women are still viewed as responsible for raising children, staying at home and taking care of household affairs (19). Furthermore, half of the women in the Iraq Woman Integrated Social and Health (I-WISH) national survey said that men are the key decision-makers in the household (Table 1). Only $50 \%$ of men had discussed the number of children that they wanted to have with their wives (19), and usually the women preferred to have a fewer children (6).

Finally, recent conflict and security instability has resulted in more restrictions and has reinforced gender roles within the community, this situation deteriorated as unemployment and poverty became more prevalent and led to high rates of teenage marriage and pregnancy (16).

\section{Husband's and family's position on family planning}

The views of the husband on FP also play a vital role in decisions on the use of contraception: many of the women surveyed in one study said they could not use contraception owing to their husband's demand (26). Women's choice of method of contraception is also influenced by the husband's preference (24). In some instances, women might be denied the right to use contraception by the husband (5) or mother-in-law (18); these are commonly reported causes of hindering utilizing FP services across different backgrounds and different cities in Iraq (23). 
Although no studies on men's involvement in FP in Iraq were identified in the search conducted for this report, the I-WISH survey reported that less than $50 \%$ of men have proper knowledge about FP and reproductive health (19).

\section{Valuing larger families}

Families in Iraq value having a high number of children (19), this was also supported by another national survey where more than half the women said they wanted 3-4 children and $15 \%$ said they wanted more than 5 (27). In addition, many women also reported using FP services for the first time only after having 3 or more children and/or reaching the desired number of children (22).

\section{Religious context}

The vast majority of Muslim scholars and leaders have approved the use of FP methods to control the size of the family and advise that women have some time for spacing between pregnancies to maintain good health and well-being (28). The I-WISH survey also revealed that only $2 \%$ cited religion as the main reason for not using FP methods (27).

\section{Discussion}

This review aimed to tackle barriers to FP services utilization and uptake. It addressed these barriers through an adapted conceptual framework taking into consideration the country context, policy, services and community and individual levels.

Civil conflict and the humanitarian crisis affected reproductive health services (including FP services) and resulted in damage to the infrastructure, attacks against health care providers and reduced quality of care (14).

At the policy level, the previous administration restricted access to FP and encouraged having more children due to wars. However, the new government recognized the role and importance of FP for development through the National Health Plan and the National Reproductive, Maternal, Neonatal, Child and Adolescent Health Strategy but not enough resources were allocated for implementation $(16,17)$.

On the other hand, at the service level, even though supplies are supposed to be offered free or heavily subsidized, most women (95\%) still have to buy these from private pharmacies and clinics (19) as products are unavailable or are misappropriated from the public sector (5). Also, there is a lack of information about the affordability and accessibility of commodities and services.

While knowledge about FP methods is generally good, there is a lack of promotional messages to women from health care providers (5). This resulted in women having to rely more on information from family and friends, with only half of the women in Basrah citing health care providers as their source of information. Lack of promotional messages could also be the reason for the high contraceptives incorrect use and unintended pregnancies among contraceptive users and contributed to misconceptions and fear of side effects among women not using contraceptives $(18,22,23)$.

Similar to affordability and accessibility, there is no information about providers' technical capacity and interaction. Yet, the average visit to a doctor lasts only 2 minutes (24), which is not enough time for FP promotion or counselling. Finally, although most contraceptive methods are available through the private sector, some women's choice of contraception is still influenced by the providers' preference (20).

This emphasizes the importance of counselling and FP promotion to address accessibility of information and commodities. Offering FP counselling as part of postpartum care visits along with FP promotion during outreach and facility-based immunization serves to tackle misconceptions (29,30). Furthermore, this can be boosted through task shifting, i.e. allowing nurses and midwives to offer FP counselling and service provision (including IUD insertion and removal and injectables) (31).

Lastly, at the community and individual level, gender roles in the household play a role where men are seen as the key decision-makers in regard to number of children; the decision on whether to use contraception and which method will be used is largely influenced by the husband's preference (20). Couples in Iraq still value having many children (half the women in one national survey said they wanted 3 or 4 ) although religion was found to be supportive of FP $(27,28)$. Community and religious leaders through men community groups can champion the use of FP for the woman and child's health to encourage discussions among couples such as in the approach implemented in Egypt $(32,33)$ and in the Islamic Republic of Iran, where clergy and religious leaders worked with health officials to design a culturally and religiously acceptable programme that contributed significantly to the success of the programme (34). Mass media and social media have both been utilized to promote smaller family size in Egypt and India (35).

\section{Conclusion}

Women in Iraq still face many barriers to accessing health care services, on top of the social, cultural and economic barriers that hinder them from receiving FP services. This review calls for an urgent need to address these barriers by providing promotional messages and counselling to women, especially as part of postpartum visits, to help them make an informed choice and tackle misconceptions. Men should also be encouraged to make mutual fertility decisions and improve their awareness about the benefits of FP and smaller families through community groups and the media.

In accordance with the findings of this review, policymakers need to support, and allocate more resources for research and FP programmes to make commodities more available in public health facilities and health care workers can spread awareness and accurate information about FP. 


\section{Acknowledgement}

I wish to thank my thesis supervisor, Dr Mahua Dass, my personal tutor, Professor John Walley, Dr Ramez Mahaini (Coordinator, WHO Regional Office for the Eastern Mediterranean) and Dr Karima Gholbzouri (Medical Officer, WHO Regional Office for the Eastern Mediterranean) for their time and support.

Funding: None.

Competing interests: None declared.

\section{Étudie des obstacles liés au recours aux services de planification familiale et à leur utilisation chez les femmes en Iraq}

\section{Résumé}

Contexte: La planification familiale permet d'éviter les grossesses non désirées et de réduire la mortalité et la morbidité maternelles. La prévalence de la contraception est encore relativement faible (58\%) en Iraq par rapport aux autres pays de la Région de la Méditerranée orientale, et les taux concernant les besoins non satisfaits (12\%) et la fécondité totale (4,2 enfants par femme) sont encore élevés. Les services sont gratuits ou fortement subventionnés dans de nombreux établissements de santé publics et privés, mais de nombreuses femmes n'y ont toujours pas recours à cause de contraintes sociales, culturelles, financières ou liées aux services de santé.

Objectifs : La présente étude exploratoire examine les obstacles liés au recours aux services de planification familiale et à leur utilisation chez les femmes en Iraq.

Méthodes : L'étude utilise un cadre conceptuel adapté à partir des cadres fondés sur la qualité des soins et les droits de l'homme pour analyser les études scientifiques publiées.

Résultats : Au niveau politique, le gouvernement soutient la planification familiale mais n'a pas alloué de ressources d'une manière suffisante. Au niveau des services, la faible promotion de la planification familiale par les prestataires de soins de santé (notamment durant les consultations prénatales) ainsi que les préjugés des prestataires en faveur de certains types de contraception ont contribué à la diffusion d'informations inexactes et d'idées fausses. Au niveau communautaire et individuel, le choix des femmes est encore largement influencé par le point de vue du mari sur la contraception, puisque les hommes sont toujours considérés comme les principaux décideurs en matière de fertilité. La valorisation d'une famille nombreuse demeure un obstacle à l'utilisation des services de planification familiale et au recours à ceux-ci, et l'on a trouvé que la religion soutenait la planification familiale.

Conclusion: Il faut diffuser des messages promotionnels et encourager les décisions mutuelles en matière de fertilité.

$$
\text { العو ائت التي تحول دون استفادة النساء من خدمات تنظيم الأسرة و استخدامها في العراق }
$$

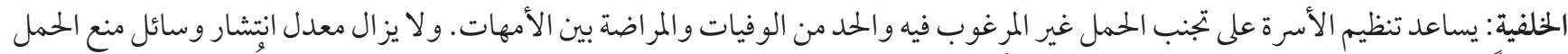

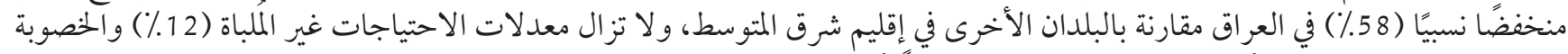

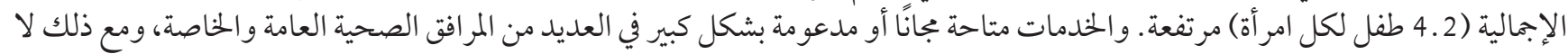

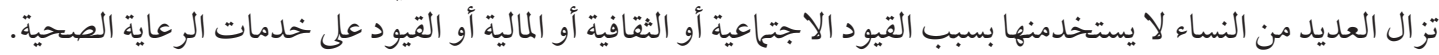
الأهداف: هدفت هذه الدراسة الاستكشافية الى تحديد العوائق التي تحول دون استفادة النساء من خدمات تنظيم الأسرة واستخدامها في العراق. طرق البحث: استخدم الاستعراض إطارًا مفاهيميًا مكيفًا من الأطُر القائمة على جودة الرعاية وحقوق الإنسان لتحليل الدراسات العلمية المنشورة.

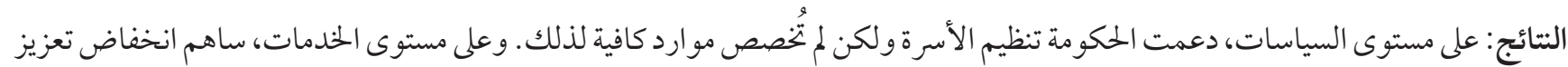

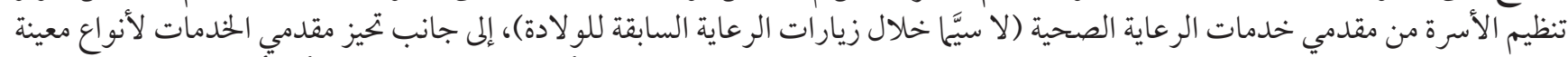

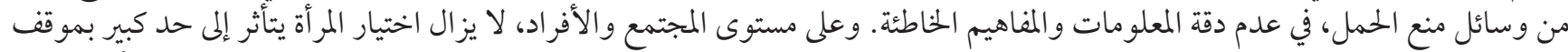

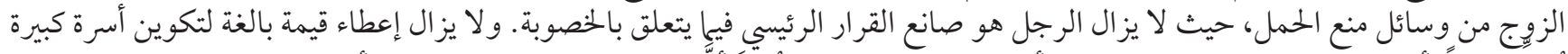

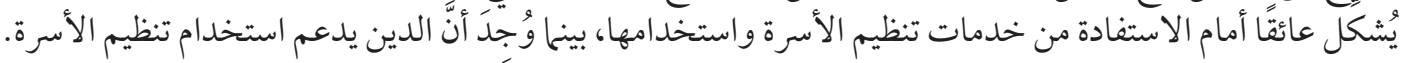

$$
\text { الاستنتاج: هناك حاجة إلى توفير رسائل تعزز وتشجع اتخاذ قرار ات الخصوبة بشكل متبادل. }
$$




\section{References}

1. Family planning/contraception. Geneva: World Health Organization; 2018 (https://www.who.int/news-room/fact-sheets/detail/ family-planning-contraception, accessed 15 May 2019).

2. Cleland J, Bernstein S, Ezeh A, Faundes A, Glasier A, Innis J. Family planning: the unfinished agenda. Lancet. 2006;368(9549):1810-1827. doi:10.1016/So140-6736(06)69480-4

3. World population dashboard. New York: United Nations Population Fund; 2019 (https://www.unfpa.org/data/world-population-dashboard, accessed 1 July 2019).

4. Multiple Indicator Cluster Survey (MICS). Baghdad: Iraq Central Statistical Organization; 2018.

5. Ebrahim SM, Muhammed NK. Knowledge, attitude and practice of family planning among women in Basrah city South of Iraq. Med J Basrah University. 2011;29(2):70-6.

6. The current situation of fertility and family planning in Iraq, challenges and interventions. Baghdad: Iraq Central Statistical Organization; 2011.

7. Hardee K, Kumar J, Newman K, Bakamjian L, Harris S, Rodríguez M, et al. Voluntary, human rights-based family planning: a conceptual framework. Stud Fam Plann. 2014;45(1):1-18. doi:10.1111/j.1728-4465.2014.00373.x

8. Bruce J. Fundamental elements of the quality of care: a simple framework. Stud Fam Plann. 1990;21(2):61-91. doi:10.2307/1966669

9. Roudi F, Monem AA, Ashford A, El-Adawy M. Women's need for family planning in Arab countries. New York: United Nations Population Fund, Population Reference Bureau; 2012:1-8.

10. Iraq urban population. New York: Trading Economics; 2016 (https://tradingeconomics.com/iraq/urban-population, accessed 18 April 2019).

11. Iraq. Virginia: The World Factbook; 2019 (https://www.cia.gov/library/publications/the-world-factbook/geos/iz.html, accessed 10 April 2019).

12. Country cooperation strategy for WHO and Iraq. Cairo: World Health Organization; 2013.

13. Shabila N, Al-Atawi N, Al-Hadidthi T, Egbert S. A qualitative assessment of the Iraqi primary healthcare system. World Health Popul. 2012;13(3):18-27. doi:10.12927/whp.2012.22817.

14. Shabila NP, Ahmed HM, Yasin MY. Women's views and experiences of antenatal care in Iraq: a Q methodology study. BMC Pregnancy Childbirth. 2014;14(1):43. doi:10.1186/1471-2393-14-43

15. Conflict and humanitarian crisis in Iraq. Geneva: World Health Organization; 2014.

16. Cetorelli V. The effect on fertility of the 2003-2011 war in Iraq. Popul Dev Rev. 2014;40(4):581-604. doi:10.1111/j.17284457.2014.00001.x

17. National Reproductive, Maternal, Newborn, Child and Adolescent Health Strategy (RMNCAH). Baghdad: Iraq Ministry of Health; 2017.

18. Agha S, Rasheed B. Family planning and unmet need among Iraqi Kurds. East Mediterr Health J. 2007;13(6):1382-91. doi:10.26719/2007.13.6.1382

19. Iraq Woman Integrated Social and Health Survey (I-WISH). Baghdad: Iraq Central Statistical Organization; 2012.

20. Noaman AM. Descriptive study of family planning methods and factors influencing their usage among women attending Tikrit Teaching Hospital. Med J Tikrit. 2010;2(162):100-7.

21. Ismael AS, Zangana JMS. Knowledge, attitudes and practice of condom use among males aged (15-49) years in Erbil Governorate. Glob J Health Sci. 2012;4(4):27. doi:10.5539/gjhs.v4n4p27

22. ALmeen MI, AL-Ayoubi LDA. Unmet need for family planning among currently married women in Baghdad Al Karkh. Iraqi J Community Med. 2016;29(4):223-9.

23. Al-Jawadi A, Al-Bakry D. Family planning unmet need profile in Mosul City, north of Iraq: a cross sectional study. Duhok Med J. 2010;4(1):41-8.

24. Tawfik-Shukor A, Khoshnaw H. The impact of health system governance and policy processes on health services in Iraqi Kurdistan. BMC Int Health Hum Rights. 2010;10(14). doi:10.1186/1472-698X-10-14

25. Raoof AM, Al-Hadithi TS. Antenatal care in Erbil city-Iraq: assessment of information, education and communication strategy. Duhok M J. 2011;5(1):31-40.

26. Nasir KM. Knowledge of women about using of family planning devices in Najaf Province. Kufa Med J. 2011;14(2):34-40.

27. Iraq Woman Integrated Social and Health Survey (I-WISH). Baghdad: Iraq Central Statistical Organization; 2012.

28. Alnakash AH. Influence of IUD perceptions on method discontinuation. Contraception. 2008;78(4):290-93. doi:10.1016/j.contraception.2008.05.009

29. High-impact practices in family planning (HIP). Immediate postpartum family planning: a key component of childbirth care. Washington, DC: USAID; 2017.

30. High-impact practices in family planning (HIP). Family planning and immunization integration: reaching postpartum women with family planning services. Washington, DC: USAID; 2013. 
31. Task sharing to improve access to family planning. Geneva: World Health Organization; 2017.

32. Abdel-Tawab NG, Loza S, Zaki A. Helping Egyptian women achieve optimal birth spacing intervals through fostering linkages between family planning and maternal/child health services. Washington, DC: Population Council; 2008.

33. High-impact practices in family planning (HIP). Community engagement: changing norms to improve sexual and reproductive health. Washington, DC: USAID; 2016.

34. Tober DM, Taghdisi MH, Jalali M. "Fewer children, better life" or "As many as God wants"?. Med Anthropol Quarterly. 2006;20(1):50-71.

35. High-impact practices in family planning (HIP). Mass media: reaching audiences far and wide with messages to support healthy reproductive behaviors. Washington, DC: USAID; 2017. 